\title{
ELSA in Industrial Robotics
}

\author{
Matthew Studley ${ }^{1}$ (D) Alan Winfield ${ }^{1}$
}

Published online: 18 August 2020

(C) The Author(s) 2020

\begin{abstract}
Purpose of Review Industry is changing; converging technologies allow a fourth Industrial Revolution, where it is envisaged that robots will work alongside humans. We investigate how the research community is responding to the ethical, legal, and social aspects of industrial robots, with a primary focus on manufacturing industry.

Recent Findings The literature shows considerable interest in the impact of robotics and automation on industry. This interest spans many disciplines, which is to be expected given that the ELS impacts of industrial robotics may be profound in their depth and far-reaching in their scope.

Summary We suggest that the increasing importance of human-robot interaction (HRI) reduces the differentiation between industrial robotics and other robotic domains and that the main challenges to successful adoption for the benefit of human life are above all political and economic. Emerging standards and legal frameworks may scaffold this success, but it is apparent that getting it wrong might have repercussions that last for generations.
\end{abstract}

Keywords Industrial robotics $\cdot$ Industry $4.0 \cdot$ Ethics $\cdot$ Socio-economic $\cdot$ Impacts

\section{Introduction}

The word, 'industry', has changed its meaning many times since its introduction to the English language in the late fifteenth century. For many people, it may conjure images of production lines and heavy manufacture. Accordingly, an industrial robot is defined by the ISO as an '...automatically controlled, reprogrammable, multipurpose manipulator, programmable in three or more axes, which can be either fixed in place or mobile for use in industrial automation applications' [1]. This definition immediately calls to mind production lines, where preprogrammed manipulators perform scripted and repetitive operations in workcells from which humans are normally excluded. The robots lack the capacity to adjust to chang-

This article belongs to the Topical Collection on Roboethics

Matthew Studley

matthew2.studley@uwe.ac.uk

Alan Winfield

alan.winfield@brl.ac.uk

1 Bristol Robotics Laboratory, University of the West of England, Coldharbour Lane, Frenchay, Bristol BS16 1QY, UK ing environments, and delicate human bodies must stay safely outside their reach.

In contrast, within the field of economics and in daily usage, the meaning of 'industry' is often taken to mean a 'particular form or sector of productive work, trade, or manufacture' [2], such as the banking industry, the car industry, the film industry, etc. Of course, a discussion of 'ELSA in Industrial Robotics' which took as its remit the applications of robotics to all commercial activity might be so broad in its scope that its usefulness might be limited. However, these contrasting meanings of 'industry' hint that our examination of ELSA should move beyond the picture of industrial robotics painted above. Might there soon be robots in manufacture which share the same awareness and adaptability as robots in assistive care settings, for example?

In this review, we will take for our main focus an understanding of industry as the production of material goods, i.e. manufacture, but we shall move beyond considering robots as the insensible occupants of workcells from which humans are prohibited. By doing this, we intend to look forward to a new paradigm for manufacturing, and the wider consequences of robotics on the world of work, and beyond. Our focus is mainly European, for it is here the new paradigm first emerged, and GDPR has shown that EU legislation can have global reach [3]. 


\section{Industry 4.0}

It has been suggested that there have been three prior industrial revolutions: the transition from hand to machine, electrification, and computerization. It is claimed that we are now witnessing a fourth Industrial Revolution (I4) [4], one characterized by interconnected processes, organizations and machines, and decentralized decision-making and enabled by nine main trends: big data, autonomous robots, simulation, additive manufacturing, the Internet of Things, cloud computing, augmented reality, horizontal and vertical integration, and cyber security [5]. Publication surveys show an annually increasing number of papers which centre on I4 [6].

The robots in I4 step beyond the confines of their predecessors' workcells and interact with humans to accomplish collaborative tasks [7]. Unlike those insensate reprogrammable manipulators, many projects foresee robots in industry as co-workers (or 'cobots' [8]) rather than mere tools. In this vision, robots' efficiency and tirelessness compensate for human frailty, while human flexibility and intelligence in turn make up for the robots' lack of understanding [9]. This coworking necessarily removes the separation of human and robot, and research on collision avoidance and impact mitigation has flourished [10॰]. Despite these challenges, it has been forecast that one-third of robots will be used for collaborative applications by 2025 [11].

A brief, and not exhaustive, roundup of current projects in the EU demonstrates a variety of approaches and areas of focus to enable this nascent field of human-robot collaboration (HRC) [7].

- An.dy focuses on predicting the actions of a cobot's human partner in order to promote safe and efficient coworking [12].

- Co4Robots is motivated by the desire to develop decentralized, real-time, automated task-planning for semi-autonomous systems with collaborating agents including humans, stationary manipulators, and mobile robotic platforms [13].

- CoLLaboratE explores a new form of co-working in which assembly tasks are automatically shared between humans and robots [14].

- SHERLOCK develops HRC applications with safe robotics, with the prediction of human intentions and future actions based on an understanding of the operational context [15].

- COVR, which aims to increase the volume of deployed cobots by addressing safety issues, providing a toolkit for identifying, and minimizing relevant risks [16].

- INCLUSIVE aims to improve human-robot cooperation through adaptive human-robot interaction (HRI), with a particular focus on supporting human users' different capabilities and needs [17].
As the preceding list shows, I4 robotics may be characterized by the same sorts of concerns as are faced in assistive robotics, predicting and interpreting humans' intentions and future actions in order to efficiently and safely add value in everyday tasks. Meanwhile, the interactions between humans and robots are characterized by teaching rather than programming [18•]. Issues in programming cobots are reviewed in [8] and, aside from the necessary safety concerns associated with robots and humans working alongside each other in close proximity [19], can be summarized as communication, optimization, and learning.

\section{Ethical}

In 2019, a survey listed 84 different sets of ethical principles for robotics and AI [20]. These principles have much in common, stating that robots and AIs should do no harm and be free of bias and deception and that they should respect human rights and freedoms and promote well-being while being transparent and dependable. Such principles also assert that the sole responsibility for robots' actions lies with their operators and/or designers [21].

Numerous papers have suggested ethical guidelines for various applications of robotics technologies, but these studies do not often focus upon the industrial use of collaborative robots. In the MATE (measure, adapt, and teach) approach outlined by Villani et al. [18•], adaptive techniques are applied to alter rate of work to the human operators, who differ in their physical ability, skill, and experience. Such approaches clearly raise ethical questions since they rely on continuous monitoring of the human co-worker. The authors investigate these using the MEESTAR approach [22], which considers many dimensions of ethical concern, at the level of the individual, the organization, and society and attempts to classify the ethical sensitivity from 'completely harmless' to 'should be opposed from an ethical viewpoint'.

Maurice et al. suggest that generic guidelines for the ethical development and use of robot systems might be insufficient when applied to industrial cobot use, though their argument would hold for many other fields of application [23]. From interviews and opinions of factory workers on collaborative robot usage scenarios, they claim that further attention is needed to ensure that robot development and use upholds human rights (e.g. by designing or training based upon datasets which are not biased by race or gender), that decision-making and actions can be transparent and accountable, and that developers and users should attempt to minimize the risk of misuse of such systems.

HRI systems might bring subtle ethical challenges beyond the immediately obvious, for example, the need in a humanrobot interaction to balance the competing interests of many different actors (users, managers, designers, customers, etc.), 
which may not be apparent and explicit to the human coworkers [24].

We suggest that there may be few ethical considerations in industrial robotics that do not apply more generally in other spheres where assistive technologies, and HRI, are used. One important difference may arise from the tendency for work environments to be coercive [25]; when workers' livelihoods depend on accepting and adapting to technological change, there is a further ethical dimension which one might not experience in HRI, e.g. in an elder-care setting. Furthermore, workers and management may find themselves locked in an arms race where the desire to avoid surveillance suggests that there is something to hide, leading to more surveillance [26]. A system based on the MATE approach is a system that continuously evaluates performance; while it might be designed to fit the system to the human, will workers worry about being stigmatized for their performance and perhaps replaced?

One of the potential benefits of I4 is the manufacture of personalized products [27], but is there any way personalization becomes ethically problematic? The automation of decision-making based on predictive models is pervasive in conceptions of I4, for example, in the behaviour of cobots to their human co-workers $[28,29]$, in decision-making about orders and supply chains $[30,31]$, or in the choice architecture presented to customers in the making of bespoke products [32]. It can be argued [33] that such algorithms are inherently value-laden and '...create moral consequences, reinforce or undercut ethical principles, and enable or diminish stakeholder rights and dignity' and that where algorithms relieve humans from the responsibility of decision-making, it should be the designer of the algorithm who is held responsible for the ethical consequences of their decisions. There seems to be a tension between the use of automation to empower the consumer through flexibility and customization and the disempowerment and inequalities which could arise through guiding their choices through the profiling inherent in recommendation systems [34].

\section{Societal}

Although it might be said that the majority of ethical issues around HRI in industrial settings are the same as those in other spheres, there are particularly wide-ranging and important societal impacts that stem from the central nature of work within peoples' lives.

\section{Economic Impacts}

One of the main worries associated with robotics and automation in industry is the replacement of human labour. Empirical studies have shown this impact from 'traditional' robotics in the recent past [35], suggesting that the impact is felt most for jobs with comparatively low skill requirements, while more qualified jobs may gain from the diffusion of industrial robots. In interviews with industrial employees, technological unemployment remains the main source of concern around the introduction of collaborative robots into the workplace [23]. Although collaborative robots are widely seen as a cause of job loss, workers also recognize they could be a potential help [36].

Some writers have suggested that the impact of robotics and automation will be rapid and massive, for example, Frey and Osborne [37] famously suggest that their analysis of O*Net labour market data in the USA shows that 'around $47 \%$ of total US employment is in the high risk category'. Technological advances are hard to predict accurately, and a recent survey comparing the estimates of experts in robotics and automation with those of non-experts suggests that, while the forecast of job replacement might be accurate, the rate at which it will occur is commonly overestimated [38].

The impact of robotics on labour markets will probably be more nuanced than sudden unemployment. In a recent survey [39] of the impact of automation in Dutch industries over a 16year period, automation increased the likelihood that workers will leave their employer, and they suffered an annual decline in wages and hours worked. This effect is more gradual than suggested by much literature predicting mass layoffs. Other studies suggest that the impact of automation on industrial workers causes a hollowing out of opportunity and wages [40]. Medium-skilled workers lose, but the (smaller percentage of) higher-skilled workers gain. Overall, robots raise productivity but not wages, and the decreasing demand for human labour tends to retain older workers but offer fewer opportunities for young aspirants.

These surveys relate more to the previous generation of industrial robotics and automation than the collaborative possibilities of I 4 cobots. It may be that investment in automation and associated I4 technologies allows higher value 'personalized' goods to be produced [41] and that this is the economic driver for companies rather than a desire to increase productivity and reduce wage bills and associated costs. Since mass production lowers costs, we expect that personalized goods will be found more at the 'luxury' end of markets. Many authors have claimed that human labour is a necessary factor for the production of value [42], but this may therefore become less true during the transition to I4.

\section{Political Impacts}

As the human worker features less in the production of value - a trend we are likely to see not only in manufacturing industry but also in those other industries where people are most usually employed, like the estimated 3.5 million professional truck drivers in the USA who stand to lose their jobs through the introduction of self-driving vehicles [43] - the 
displaced may tend towards radical political change. In the 2016 US Presidential Election, Frey et al. found 'robust evidence of a relationship between electoral districts' exposure to automation and their share of voters supporting Donald Trump', and this support was particularly high in areas characterized by low-educated males in routine jobs [44]. This radicalization is one of the ways in which the impact of automation in industry goes beyond the individual. Modern Luddites might not smash looms, but political systems.

Mention of Luddites and the attendant Fallacy reminds us that, while new technologies might make old jobs redundant, it creates new niches and opportunities in turn. While some authors are sanguine about this renewal [45], others predict that the reduction in employment prospects for lower-skilled workers will contribute to rising inequality and that it may take generations to compensate for the fall in wages [46]. Unemployment and lower wages will lead to a fall in taxation revenue (especially in countries like the USA where the taxation regime incentivises companies' investment in capital over human labour and its associated tax costs [47]), and the revenue available to Government will necessarily fall. This might be a 'double whammy' as the maintenance of the unemployed and costs of retraining and education may fall mostly on the State. Unsurprisingly, we and others have suggested changes to taxation, perhaps in the form of a robot tax, which has been shown to narrow the wage gap between skilled and unskilled labour [48] in a variety of different modelled scenarios. In contrast, some authors suggest that a universal basic income which would be funded by a tax on the value created through industry, at the point that value is distributed in wages or dividends, could be an adequate and effective way to ameliorate the impact of technological change [49].

\section{Psychological and Sociological Impacts}

Working practices have impacts beyond the economic. Cobots might be rapidly repurposed to work on different tasks in hybrid teams, but the organizational structure of these teams, and the way in which they are tasked and managed, may need to change according to the nature of the job, the identity and skills of the players, and the organizational environment. Some authors have explored the use of tools based on managerial approaches used in I4, which will automatically organize a team for each task that needs to be performed [50]. In a highly agile and adaptive workplace, this process might itself draw upon automated decision-making and machine learning to continually optimize the ways in which humans and machines are used.

A recent survey of publications in HRI and Human Resources Management [51] suggests that few studies ask how to manage and support the human resources in collaborative robotic environments. Workers in fluid organizational structures, continuously optimized and surrounded by technology, may experience increasing levels of 'technostress' [52], decreasing their engagement and satisfaction at work. One consequence of increasing automation is that 'low skill' workers have to adapt to more challenging roles, further overburdening them and challenging their mental health [53].

One feature of current automation, where the flexibility and dexterity of humans fill the gaps in workflow stages that are yet to be automated, is the stress experienced by workers, as these testimonies bear witness:

I wasn't prepared for how exhausting working at Amazon would be. It took my body two weeks to adjust to the agony of walking 15 miles a day and doing hundreds of squats. But as the physical stress got more manageable, the mental stress of being held to the productivity standards of a robot became an even bigger problem. [54]

...injuries were more common in warehouses with the robots, which makes sense because it's the pace that's the problem, and the machines that most concern workers are the ones that enforce it. [55]

Here the human work rate is determined by the needs of the machine, quite contrary to the approach advocated in [23]. It is clear that, for the individual, there may be impacts of working with robots beyond the economic. Should we then welcome the eventual replacement of the human in industry?

Since Aristotle, work in the West has long been regarded as either praxis (work done for its own sake) or poiesis (work done to produce something useful). The latter conception dominates most people's relationship with work; we work to earn money, to pay the bills. Work is more than this though. It is recognized that unemployment is bad for physical and mental health and well-being and that this is not just due to a reduction in income [56]. Self-esteem is bound up in our opinion of our own competence, in others' recognition of this, and in the comparisons, we make to those around us [57]. Furthermore, it has been argued [58] that working together binds us to society through a recognition of our mutual dependence and is one of the prime creators of personal identity [59] and meaning in the semiotic sense [60]. Whether this remains true in the future will depend not only on the impacts of automation but also on the sociopolitical system in which these impacts occur.

\section{Legal}

It has been suggested that, while there are many headlinegrabbing projects in industrial collaborative robots, takeup 
has been relatively slow and that this may be due to safety considerations stemming from the complexity of the problems [61]. However these concerns are addressed, the wider use of robots requires a legal framework capable of supporting innovation while protecting rights and values.

The 2017 Resolution of the European Parliament [62] outlines several areas in which developments in robotics may require new sets of rules to be adopted into legal frameworks. This resolution was partly based on the outputs of the EC FP7 'Robolaw' project [63]. There is no specific robotic legislation in the EC as yet, and industrial robots are regulated by the Machinery Directive, also falling under cross-cutting legislation such as the Directive on Liability for Defective Products and the Product Safety Directive. The position is further complicated by the lack of a legal definition of the term 'robot' [64], a lack which the resolution recognizes must be addressed. Given the variety of potential robotic devices and the uses to which they could be put, it is unlikely that there could be a single set of 'laws for robots' [65•], even within a single regulatory domain such as the EU. There are numerous challenges to regulators, e.g. how to keep up with technological advances, how to balance innovation and the protection of rights and values, whether to maintain the moral status quo or 'nudge' social norms, and how to balance effectiveness against legitimacy $\left[65^{\circ}\right]$.

\section{Liability}

Proving liability ('responsible or answerable in law; legally obligated' [66]) is key within legal frameworks. Current legal regimes could be the special liability of the designer and the programmer for defective products [67], but the introduction of robotics and AI into industry challenges existing notions. With closer co-working and with the penetration of AI into scheduling, organizational and operational frameworks, etc., the attribution of liability may become blurred. For example, consider harm arising from the actions of a robot in a team of humans and robots working together. Equally, in workflows involving multiple cyber-physical entities, robots may enter into associations and contracts autonomously, e.g. through 'smart contracts' [68]. The consequences of failure might go far beyond that permitted by the operator/owner of the robot.

Current legislation which creates a scheme of strict product liability for damage arising from defective products [69] is insufficient for learning robots 'since those robots would autonomously learn from their own variable experience and interact with their environment in a unique and unforeseeable manner' [62].

\section{Personhood}

Some authors have argued [70] that the autonomy and agency of robots could confer upon them a form of personhood, similar to the notion of corporate personhood, by which some of the rights ascribed to individuals can be enjoyed by a corporation, independently of its officers, employees, and staff. Within law, a 'person' has the rights and duties of a human being; indeed, rights and duties can only be the properties of persons [71]. Currently, it is the case that autonomy and selfdetermination are not in themselves sufficient to confer legal personhood, as in the case of chimpanzees, as they are 'incapable of bearing any legal responsibilities and societal duties' [72]. Similarly, within current definitions of personhood, robots could not be persons. While robotic personhood might promote innovation by limiting the liability of manufacturers and operators, it can be argued that the costs of creating a new class of legal entity are unjustified by the potential benefits and that the data gathered and stored in robots' 'black boxes' [73] might provide sufficient evidence for liability to be easily and accurately determined [74]. Indeed, we argue that the field of robot accident investigation is a necessity as robots come to inhabit our space [75].

The interesting possibility of a 'retribution gap' is raised by Danaher [76]. It has been observed that people need, and derive value from, somebody to blame when things go wrong. For the injured to get value from this, the object of blame must suffer consequences; but a robot that caused an accident cannot pay retribution in the way a human can [77], while the designers and operators, Danaher argues, may be too attenuated from the event to be adequate targets for our ire. Industrial accidents could perhaps leave victims looking for somebody - anybody - to blame, challenging the rule of law and the legitimacy of legal systems.

\section{Data and Privacy}

As previously mentioned [18•], cobots can gather data to adapt to the workrate, abilities, and needs of their human coworkers. This data may be processed offboard the robot in cloud services, and the data, and models derived from it, might be used by other robots or organizations [78]. Within the European Data Protection Framework (GDPR), consent has to be given by the data subject for this gathering and storage of personal data, which may prove complex when robot systems are themselves a network of distributed processes and when a robot's sensors are capable of gathering data about much more than their co-worker.

\section{Standards}

While there are many sets of principles for ethical robot development, principles are not practice [21]. The publication of BS8611 in 2016 [79] identified 20 classes of ethical hazard and presents guidance on how to perform an ethical risk assessment and take action to reduce or mitigate impacts. Also in 2016, the IEEE Standards Association launched a Global 
Initiative on Ethics of Autonomous and Intelligent Systems [80] to place human well-being at the core of robotics development, now with 14 working groups drafting the IEEE P7000 series human standards. Compliance with such standards might become a requirement for a licence to operate and could be the basis for codes of conduct adopted on a voluntary basis. Such self-policing methods may avoid the need for widespread statutory regulation and fill in the gaps between 'regulatory approaches based on a strong framework of rights and values' $[65 \bullet]$.

\section{Conclusions}

Industrial robots are more than pre-programmed manipulators. Industry is more than manufacture, and industrial and service robotics are converging in expectation of collaborative applications which enable more widespread use of robots. Due to the pivotal nature of work in most adult lives, the ethical, legal, and societal impacts of industrial robotics might be more profound than those of robots in other sectors, e.g. military or healthcare. Moreover, the impacts industrial robots may be dangerously easy to overlook - precisely because robots are already commonplace in the manufacturing and logistics industries.

As with any technology, the impacts will be determined by the context in which these robots are used. While standards and regulation can mitigate against many harms, the most widespread and profound impacts will depend on the economic and political system which motivates the adoption of robots to the workplace.

This is a high stakes game. We hope that human well-being will be placed at the heart of robotics development.

\section{Compliance with Ethical Standards}

Conflict of Interest The authors declare that they have no conflict of interest.

Human and Animal Rights and Informed Consent This article does not contain any studies with human or animal subjects performed by any of the authors.

Open Access This article is licensed under a Creative Commons Attribution 4.0 International License, which permits use, sharing, adaptation, distribution and reproduction in any medium or format, as long as you give appropriate credit to the original author(s) and the source, provide a link to the Creative Commons licence, and indicate if changes were made. The images or other third party material in this article are included in the article's Creative Commons licence, unless indicated otherwise in a credit line to the material. If material is not included in the article's Creative Commons licence and your intended use is not permitted by statutory regulation or exceeds the permitted use, you will need to obtain permission directly from the copyright holder. To view a copy of this licence, visit http://creativecommons.org/licenses/by/4.0/.

\section{References}

Papers of particular interest, published recently, have been highlighted as:

- Of importance

1. BS ISO 8373:2012 - Robots and robotic devices. Vocabulary. In: BSI. https://shop.bsigroup.com/ProductDetail/?pid= 000000000030218324. Accessed 7 Jul 2020

2. James S. Oxford English Dictionary Online20002880xford English Dictionary Online. Oxford: Oxford University Press 2000. online database www.oed.com. Ref Rev. 2000;14:20-2.

3. Li H, Yu L, He W. The impact of GDPR on global technology development. J Glob Inf Technol Manag. 2019;22:1-6.

4. Lasi H, Fettke P, Kemper H-G, Feld T, Hoffmann M. Industry 4.0. Bus Inf Syst Eng. 2014;6:239-42.

5. Erboz G. How to define industry 4.0: main pillars of industry 4.0. Gödöllö: Szent Istvan University; 2017. p. 1-9.

6. Lu Y. Industry 4.0: a survey on technologies, applications and open research issues. J Ind Inf Integr. 2017;6:1-10.

7. Colgate E, Bicchi A, Peshkin MA, Colgate JE. Safety for physical human-robot interaction. In: Springer handbook of robotics. Springer, 2008; pp. 1335-1348.

8. El Zaatari S, Marei M, Li W, Usman Z. Cobot programming for collaborative industrial tasks: an overview. Rob Auton Syst. 2019;116:162-80.

9. Müller R, Vette M, Mailahn O. Process-oriented task assignment for assembly processes with human-robot interaction. Procedia CIRP. 2016;44:210-5.

10. Robla-Gómez S, Becerra VM, Llata JR, González-Sarabia E, Torre-Ferrero C, Pérez-Oria J. Working together: a review on safe human-robot collaboration in industrial environments. IEEE Access. 2017;5:26754-73 An excellent overview of technologies, standards and approaches to meet the physical safety challenges involved in transitioning robots to collaborative industrial roles.

11. Zanchettin AM, Croft E, Ding H, Li M. Collaborative robots in the workplace [from the guest editors]. IEEE Robot Autom Mag. 2018;25:16-7.

12. Ivaldi S, Fritzsche L, Babič J, Stulp F, Damsgaard M, Graimann B, Bellusci G, Nori F. Anticipatory models of human movements and dynamics: the roadmap of the andy project. 2017.

13. Menghi C, Tsigkanos C, Pelliccione $\mathrm{P}$, Ghezzi C, Berger T. Specification patterns for robotic missions. IEEE Trans Softw Eng. 2019:1-1.

14. Macovetchi A-M, Kirstein F, Doulgeri Z, Dimeas F A methodology to formulate user requirements for designing collaborative robots.

15. Andrianakos G, Dimitropoulos N, Michalos G, Makris S. An approach for monitoring the execution of human based assembly operations using machine learning. Procedia CIRP. 2019;86:198-203.

16. Bessler J, Schaake L, Bidard C, Buurke JH, Lassen AEB, Nielsen $\mathrm{K}$, Saenz J, Vicentini F. COVR - towards simplified evaluation and validation of collaborative robotics applications across a wide range of domains based on robot safety skills. Biosystems \& Biorobotics. 2019; 123-126.

17. Villani V, Sabattini L, Czerniaki JN, Mertens A, Vogel-Heuser B, Fantuzzi C (2017) Towards modern inclusive factories: a methodology for the development of smart adaptive human-machine interfaces. In: 2017 22nd IEEE international conference on emerging technologies and factory automation (ETFA). pp 1-7.

18. Villani V, Sabattini L, Czerniak JN, Mertens A, Fantuzzi C. MATE robots simplifying my work: the benefits and socioethical implications. IEEE Robot Autom Mag. 2018;25:37-45 A description of an approach to adapt a robot system to the human co-worker 
which explores the ELS impacts of such systems in general, an approach to their ethical assessment, and feedback gathered from industrial workers with special needs and requirements.

19. Haddadin S, Croft E. Physical human-robot interaction. In: Siciliano B, Khatib O, editors. Springer handbook of robotics. Cham: Springer International Publishing; 2016. p. 1835-74.

20. Jobin A, Ienca M, Vayena E. The global landscape of AI ethics guidelines. Nature Machine Intelligence. 2019;1:389-99.

21. Winfield A. Ethical standards in robotics and AI. Nature Electronics. 2019;2:46-8.

22. Manzeschke A, Weber K, Rother E, Fangerau H. Ethical questions in the area of age appropriate assisting systems. VDI/VDE Innovation+ Technik GmbH: German Federal Ministry of Education and Research; 2015.

23. Maurice P, Allienne L, Malaisé A, Ivaldi S. Ethical and social considerations for the introduction of human-centered technologies at work. In: 2018 IEEE workshop on advanced robotics and its social impacts (ARSO). ieeexplore.ieee.org. 2018; pp 131-138.

24. Arnold T, Scheutz M. Beyond moral dilemmas: exploring the ethical landscape in HRI. In: 2017 12th ACM/IEEE international conference on human-robot interaction HRI. 2017; pp 445-452.

25. Beirne M, Ramsay H. Information technology and workplace democracy: Routledge; 2018.

26. Anteby M, Chan CK. A self-fulfilling cycle of coercive surveillance: workers' invisibility practices and managerial justification. Organ Sci. 2018;29:247-63.

27. Ghobakhloo M. The future of manufacturing industry: a strategic roadmap toward industry 4.0. Int J Manuf Technol Manag. 2018;29:910-36.

28. Liu H, Wang L. Human motion prediction for human-robot collaboration. J Manuf Syst. 2017;44:287-94.

29. Luo R, Hayne R, Berenson D. Unsupervised early prediction of human reaching for human-robot collaboration in shared workspaces. Auton Robots. 2018;42:631-48.

30. Wenzel H, Smit D, Sardesai S (2019) A literature review on machine learning in supply chain management. In: Artificial intelligence and digital transformation in supply chain management: innovative approaches for supply chains. Proceedings of the Hamburg International Conference of Logistics (HICL), Vol. 27. Berlin: epubli GmbH, pp 413-441.

31. Shutay J, Ahern J. Transforming supply chains through integrated business planning supported by advanced technologies. Journal of Supply Chain Management, Logistics and Procurement. 2018;1: 358-67.

32. Loef J, Joseph PIIB, Robben H. Co-creating customization: collaborating with customers to deliver individualized value. Strateg Leadersh. 2017;45:10-5.

33. Martin K. Ethical implications and accountability of algorithms. J Bus Ethics. 2019;160:835-50.

34. Milano S, Taddeo M, Floridi L. Recommender systems and their ethical challenges. AI Soc. 2020. https://doi.org/10.1007/s00146020-00950-y.

35. Edler D, Ribakova T. The impact of industrial robots on the level and structure of employment in Germany - a simulation study for the period 1980-2000. Technol Forecast Soc Chang. 1994;45:25574.

36. Elprama SA, Jewell CIC, Jacobs A, El Makrini I, Vanderborght B. Attitudes of factory workers towards industrial and collaborative robots. In: Proceedings of the companion of the 2017 ACM/IEEE international conference on human-robot interaction. New York, NY, USA: Association for Computing Machinery; 2017. p. 113-4.

37. Frey CB, Osborne MA. The future of employment: how susceptible are jobs to computerisation? Technol Forecast Soc Change. 2017;114:254-80.

38. Walsh T. Expert and non-expert opinion about technological unemployment. Int J Autom Comput. 2018;15:637-42.
39. Bessen JE, Goos M, Salomons A, Van den Berge W. Automatic reaction - what happens to workers at firms that automate? Boston Univ School of. 2019. https://doi.org/10.2139/ssrn.3328877.

40. Dauth W, Findeisen S, Suedekum J, Woessner N. German robots the impact of industrial robots on workers. 2017.

41. Wang Y, Ma H-S, Yang J-H, Wang K-S. Industry 4.0: a way from mass customization to mass personalization production. Adv Manuf. 2017;5:311-20.

42. Marx K. Capital: a critique of political economy. The process of circulation of capital. Progress. 1986

43. Solon O. Self-driving trucks: what's the future for America's 3.5 million truckers? The Guardian. 2016

44. Frey CB, Berger T, Chen C. Political machinery: automation anxiety and the 2016 US presidential election: University of Oxford; 2017.

45. Stromquist NP. World development report 2019: the changing nature of work. Int Rev Educ. 2019;65:321-9.

46. Berg A, Buffie EF, Zanna L-F (2018) Should we fear the robot revolution? (the correct answer is yes). In: IMF. https://www.imf. org/en/Publications/WP/Issues/2018/05/21/Should-We-Fear-theRobot-Revolution-The-Correct-Answer-is-Yes-44923. Accessed 1 Jul 2020.

47. Kovacev R. A taxing dilemma: robot taxes and the challenges of effective taxation of AI, Automation and Robotics in the Fourth Industrial Revolution. 2020

48. Zhang P. Automation, wage inequality and implications of a robot tax. Int Rev Econ Finance. 2019;59:500-9.

49. Straubhaar T. On the economics of a universal basic income. Intereconomics. 2017;52:74-80.

50. Shehadeh MA, Schroeder S, Richert A, Jeschke S. Hybrid teams of industry 4.0: a work place considering robots as key players. In: 2017 IEEE international conference on systems, man, and cybernetics (SMC). ieexplore.ieee.org 2017; pp 1208-1213.

51. Libert K, Mosconi E, Cadieux N (2020) Human-machine interaction and human resource management perspective for collaborative robotics implementation and adoption. Proceedings of the 53rd Hawaii International Conference on System Sciences. https://doi. org/10.24251/HICSS.2020.066.

52. Atanasoff L, Venable MA. Technostress: implications for adults in the workforce. Career Dev Q. 2017;65:326-38.

53. Brinzer B, Banerjee A. Measuring the human aspect: the key for managing the complexity in production. In: Advances in ergonomics of manufacturing: managing the enterprise of the future: Springer International Publishing; 2018. p. 14-24.

54. Guendelsberger E, On the Clock (2019) I worked at an Amazon fulfillment center; They Treat Workers Like Robots. Time.

55. Dzieza J (2020) How hard will the robots make us work? In: The Verge. https://www.theverge.com/2020/2/27/21155254/ automation-robots-unemployment-jobs-vs-human-google-amazon. Accessed 2 Jul 2020.

56. Wanberg CR. The individual experience of unemployment. Annu Rev Psychol. 2012;63:369-96.

57. Schwalbe ML. Sources of self-esteem in work: what's important for whom? Work Occup. 1988;15:24-35.

58. Durkheim E. Durkheim: the division of labour in society. Macmillan International Higher Education. 2013.

59. Gini A. Work, identity and self: how we are formed by the work we do. J Bus Ethics. 1998;17:707-14.

60. Halliday MAK. Language as social semiotic. The Discourse Studies Reader Amsterdam: John Benjamins. 2014; 263-272.

61. Saenz J, Elkmann N, Gibaru O, Neto P (2018) Survey of methods for design of collaborative robotics applications- why safety is a barrier to more widespread robotics uptake. Proceedings of the 2018 4th international conference on mechatronics and robotics engineering - ICMRE 2018. https://doi.org/10.1145/3191477. 3191507 
62. Delvaux M, et al. Draft report with recommendations to the commission on civil law rules on robotics. European Parliament: Brussels, Belgium. 2016; 22.

63. Palmerini E, Bertolini A, Battaglia F, Koops B-J, Carnevale A, Salvini P. RoboLaw: towards a European framework for robotics regulation. Rob Auton Syst. 2016;86:78-85.

64. Molyneux CG, Oyarzabal R. What is a robot (under EU law). RAIL. 2018;1:11-6.

65. Leenes R, Palmerini E, Koops B-J, Bertolini A, Salvini P, Lucivero F. Regulatory challenges of robotics: some guidelines for addressing legal and ethical issues. Law, Innovation and Technology. 2017;9:1-44 An excellent overview of the challenges in regulating robotics to protect rights and standards while fostering innovation, with a focus on the European legal framework.

66. Black's Law Dictionary, 11th. Reuters

67. Rault R, Trentesaux D. Artificial intelligence, autonomous systems and robotics: legal innovations. In: Borangiu T, Trentesaux D, Thomas A, Cardin O, editors. Service orientation in Holonic and multi-agent manufacturing: proceedings of SOHOMA 2017. Cham: Springer International Publishing; 2018. p. 1-9.

68. Fotiou N, Polyzos GC. Smart contracts for the internet of things: opportunities and challenges. 2018 European conference on networks and communications (EuCNC). 2018; https://doi.org/10. 1109/eucnc.2018.8443212

69. Fairgrieve D, Goldberg RS. Product liability. Oxford University Press. 2020

70. Leroux C, Labruto R, Boscarato C, Caroleo F, Günther JP, Löffler $\mathrm{S}$, Hilgendorf E. Suggestion for a green paper on legal issues in robotics. Contribution to Deliverable D 3: 2012

71. Topulos K, Elliott J. Butterworths' Australian legal dictionary. General editors: Peter E. Nygh and Peter Butt. Sydney: Butterworths, 1997. Pp. xxxii, 1344. Int J Leg Inf. 1997;25:245-6.
72. Solaiman SM. Legal personality of robots, corporations, idols and chimpanzees: a quest for legitimacy. Artif Intell Law. 2017;25:15579 .

73. Winfield AFT, Jirotka M (2017) The case for an ethical black box. In: Towards autonomous robotic systems. Springer International Publishing, pp. 262-273.

74. Wagner G. Robot, Inc: personhood for autonomous systems. Fordham Law Rev. 2019;88:591.

75. Winfield AFT, Winkle K, Webb H, Lyngs U, Jirotka M, Macrae C. Robot accident investigation: a case study in responsible robotics. arXiv [cs.RO]. 2020

76. Danaher J. Robots, law and the retribution gap. Ethics Inf Technol. 2016;18:299-309.

77. Asaro PM. 11 a body to kick, but still no soul to damn: legal perspectives on robotics. Robot ethics: The ethical and social implications of robotics, 2011; 169 .

78. Simoens P, Dragone M, Saffiotti A. The internet of robotic things: a review of concept, added value and applications. Int J Adv Robot Syst. 2018;15:1729881418759424.

79. Bsi-2016 (2016) BS 8611: 2016 Robots and Robotic Devices: Guide to the Ethical Design and Application of Robots and Robotic Systems.

80. IEEE SA - The IEEE Global Initiative on Ethics of Autonomous and Intelligent Systems. https://standards.ieee.org/industryconnections/ec/autonomous-systems.html. Accessed 6 Jul 2020

Publisher's Note Springer Nature remains neutral with regard to jurisdictional claims in published maps and institutional affiliations. 